\title{
Aging of Rejuvenated Asphalt Binders
}

\author{
Mojtaba Mohammadafzali, ${ }^{1}$ Hesham Ali, ${ }^{1}$ James A. Musselman, \\ Gregory A. Sholar, ${ }^{3}$ and Wayne A. Rilko ${ }^{3}$ \\ ${ }^{1}$ Department of Civil and Environmental Engineering, Florida International University, Miami, FL, USA \\ ${ }^{2}$ Oldcastle Materials Group, FL, USA \\ ${ }^{3}$ State Material Office, Florida Department of Transportation, Gainesville, FL, USA
}

Correspondence should be addressed to Mojtaba Mohammadafzali; mmoha020@fiu.edu

Received 15 April 2017; Accepted 8 June 2017; Published 7 August 2017

Academic Editor: Hainian Wang

Copyright (C) 2017 Mojtaba Mohammadafzali et al. This is an open access article distributed under the Creative Commons Attribution License, which permits unrestricted use, distribution, and reproduction in any medium, provided the original work is properly cited.

\begin{abstract}
An important concern that limits the RAP content in asphalt mixtures is the fact that the aged binder that is present in the RAP can cause premature cracking. Rejuvenators are frequently added to high RAP mixtures to enhance the properties of the binder. There is no existing method to predict the longevity of a rejuvenated asphalt. This study investigated the aging of rejuvenated binders and compared their durability with that of virgin asphalt. Various samples with different types and proportions of RAP, virgin binder, and rejuvenator were aged by RTFO and three cycles of PAV. DSR and BBR tests were conducted to examine the high-temperature and low-temperature rheological properties of binders. Results indicated that the type and dosage of the rejuvenator have a great influence on the aging rate and durability of the binder. Some rejuvenators make the binder age slower, while others accelerate aging. These observations confirm the importance of evaluating the long-term aging of recycled binders. For this purpose, critical PAV time was proposed as a measure of binder's longevity.
\end{abstract}

\section{Introduction}

To maintain over 2.4 million miles of asphalt surfaced roads in the US, over one hundred million tons of asphalt pavement is milled and resurfaced every year. The milled asphalt material, which is reclaimed asphalt pavement (RAP), is entirely recyclable [1]. Despite an abundance of this valuable resource, some portions of RAP are still wasted in landfills, and yet another part of it is used in nonasphalt applications, such as an embankment, subbase, base, and shoulder. Therefore, the majority of the RAP is not recycled to its highest potential.

Asphalt mixtures with more than 25\% RAP are often identified as high RAP mixtures $[2,3]$. One of the most important obstacles for using high RAP asphalt mixtures is a lack of confidence in their performance [4]. A high RAP mixture can perform differently from a conventional mixture, and currently, there are no adequate methods to predict and assess all aspects of these differences. Aging of the asphalt binder is among most critical parameters that make recycled asphalt mixtures different from new material. When pavement ages, the asphalt binder becomes hard, brittle, and prone to cracking [5-7]. The reason for this phenomenon is that lighter components of the asphalt or maltenes are partially lost due to evaporation and oxidation. Rejuvenating is the process of restoring the original properties of an aged asphalt binder by adding a rejuvenator or recycling agent (RA). Rejuvenation is often perceived as simply softening the hard asphalt. Therefore, in most cases, specifications call for a target range of penetration, viscosity, or performance grade (PG) to verify the effectiveness of rejuvenation $[8$, 9]. However, there are other concerns that differentiate a rejuvenated binder from a virgin binder that cannot be addressed by these requirements. The durability of the binder is one of these issues.

Today, decades after recycling of asphalt pavement became a common practice in the late 1970s, rejuvenated mixtures are aging again, and their aging behavior is not necessarily similar to that of virgin mixtures. Therefore, it is important to study the aging of recycled asphalt and compare it to that of virgin binders. To achieve a high RAP mixture 
with durability similar to that of new pavement material, the rejuvenated asphalt binder should not age faster than a virgin asphalt.

Terrel and Fritchen compared the durability of recycled and virgin mixtures in 1978 [10]. They simulated long-term moisture damage using a vacuum-submerged conditioning procedure, followed by several freeze-thaw thermal cycles. Results showed that the performance of recycled asphalt concrete samples was similar to new samples. In another study, virgin and recycled mixtures were subjected to longterm oven aging [11]. Dynamic modulus tests showed that samples that contained RAP aged slower. It should be noted that no rejuvenator was added to the mixtures in this study. The emergence of the Superpave performance grade system and its tests and aging procedures provided new tools for evaluating the changes in asphalt properties as it ages. A study that evaluated the performance of recycled asphalt binders using the performance grade system concluded that generally recycled asphalt binders perform similar to or better than virgin binders [12]. Aging was simulated by oven heating of mixtures. Results from this study confirmed the ability of rejuvenators to effectively lower the PG of samples containing up to $45 \%$ RAP. It was concluded from a series of shear modulus master curves that using recycling agents in mixtures containing RAP improves fatigue cracking resistance without adversely affecting rutting resistance. Also, it has been showed that the use of an excessively aged binder in recycled mixtures can also lead to segregation problems due to a reduction in binder's adhesion [13].

While the majority of the previous researches on the durability of recycled asphalt show a better longevity for recycled material, there are instances that conclude vice versa. According to a study that used Rolling Thin Film Oven (RTFO) and Pressure Aging Vessel (PAV) for simulating the aging and Fourier Transformed Infrared Spectroscopy for evaluating the level of aging, rejuvenated binder generally aged faster than virgin binder [14]. There is a need to study the parameters that affect the longevity of rejuvenated binder and cause them age faster or slower in comparison with virgin asphalt. In a previous research by the authors, the aging of $100 \%$ recycled asphalt binders was evaluated $[15,16]$. In that study, the PAV was used to simulate long-term aging. The results showed that aging of recycled asphalt could be either faster or slower than that of virgin asphalt, depending on the rejuvenator used. The difference in the service lives of binders rejuvenated by different products was estimated to be up to ten years. Also, it was shown that the standard PAV aging time was not adequate to evaluate aging behavior. Therefore, aging for a longer period of time is required to ensure the durability of recycled asphalt.

There is a well-recognized need to increase the use of RAP in the pavement. However, this cannot be achieved if asphalt rejuvenation continues to be perceived as simply softening the binder. This paper presents an effort to overcome this shortcoming by addressing the need for an effective rejuvenation. The objective of this research was to evaluate the durability of asphalt binders containing RAP. Rheological properties of the binder were used to assess the level of aging. The long-term aging of binders with 20 and 40 percent RAP was compared to that of virgin asphalt binders. The effect of different rejuvenators on the durability was also investigated.

\section{Materials and Methods}

2.1. Experimental Approach. The experimental approach was designed based on Superpave PG tests and aging procedures. The aging was simulated by the PAV, which exposes the asphalt to heat and high pressure. The standard PAV aging time is 20 hours. There is no definite correlation between PAV aging and actual field aging time, but a study performed in Florida for this purpose estimated that the aging caused by a 20-hour PAV cycle is equivalent to 8 years of service [17]. This estimate was used to provide an approximate correlation between PAV time and field aging. Furthermore, it was aimed to look at the aging beyond the first 8 years. Therefore, samples were subjected to three PAV cycles to increase the PAV aging time to 60 hours and simulate almost 24 years of in-service aging.

One of the objectives of this research was to introduce a quantitative description for binder durability. For this purpose, the PAV time that increases the high-temperature PG of each sample from $70^{\circ} \mathrm{C}$ to $95^{\circ} \mathrm{C}$ was considered as a measure of aging that makes the binder too hard to perform well. This value is referred to as critical PAV time in this paper. Based on the Florida Department of Transportation's testing of over 21 RAP stockpiles, a high-temperature PG of $95^{\circ} \mathrm{C}$ is the typical grade of a RAP binder in Florida. Each sample was subjected to four levels of aging, which included RTFO aging and three cycles of PAV aging. After each level, the samples underwent Dynamic Shear Rheometer (DSR) testing. The primary parameter used for characterizing the stiffness of the binder and thereafter the level of aging was the continuous high-temperature performance grade of the binder. This parameter is briefly referred to as high $P G$ in this paper. Also, the low-temperature properties of the binders were assessed by Bending Beam Rheometer (BBR) tests after standard (20 hours) and extended (60 hours) PAV aging.

2.2. Material. Two types of nonmodified RAP, two virgin binders, and two rejuvenators were used. Samples were prepared with $20 \%$ and $40 \%$ content of RAP binder.

2.2.1. RAP Binders. A medium-aged RAP and a hard RAP, recently milled in Florida, were used. These are referred to as RAP 1 and RAP 2, respectively. The RAP binder was recovered using a centrifuge extractor and a rotary evaporator in accordance with ASTM D2172 and ASTM D5404. Trichloroethylene was used as the solvent for the binder recovery process.

2.2.2. Virgin Binders. Two types of virgin binders were used. These are referred to as VB1 and VB2. Although both binders had an incremental grade of PG 67-22, the continuous grade of VB1 was slightly higher than VB2. Table 1 presents results from the high-temperature DSR tests on RAP and virgin binders and the resulting high PG values. The RTFO mass loss was $0.61 \%$ for $\mathrm{VB} 1$ and $0.43 \%$ for VB2. 
TABLE 1: DSR test results for RAP and virgin binders.

\begin{tabular}{lcccc}
\hline Binder & $\begin{array}{c}\text { Test temperature } \\
\left({ }^{\circ} \mathrm{C}\right)\end{array}$ & $\begin{array}{c}\delta \\
\left({ }^{\circ}\right)\end{array}$ & $\begin{array}{c}G^{*} / \sin \delta \\
(\mathrm{kPa})\end{array}$ & $\begin{array}{c}\text { High PG } \\
\left({ }^{\circ} \mathrm{C}\right)\end{array}$ \\
\hline RAP 1 (medium) & 82 & 82 & 3.25 & 91.95 \\
\multirow{2}{*}{ RAP 2 (hard) } & 88 & 84 & 1.60 & \\
& 82 & 76 & 14.60 & 104.24 \\
VB1 (not aged) & 88 & 79 & 7.08 & \\
& 67 & 86 & 1.48 & 70.19 \\
VB2 (not aged) & 76 & 86 & 0.49 & \\
& 67 & 88 & 1.29 & 69.18 \\
VB1 (RTFO aged) & 76 & 88 & 0.45 & \\
& 67 & 83 & 3.68 & 70.97 \\
VB2 (RTFO aged) & 73 & 85 & 1.69 & \\
& 67 & 85 & 2.77 & 68.86 \\
\hline
\end{tabular}

2.2.3. Recycling Agents. Two recycling agents (rejuvenators) were used. These are commercial products that are commonly used in Florida, referred to as RA1 and RA2.

RA1 is a dark yellow heavy paraffinic oil with high aromatic content that gives it good softening power. The rejuvenator contains no asphaltene. This helps restore the maltene to asphaltene ratios that are reduced by aging. The flash point of this oil was $420^{\circ} \mathrm{F}\left(216^{\circ} \mathrm{C}\right)$ as determined by the Cleveland Open Cup Test (ASTM D92). The material has good high-temperature stability and does not emit much smoke at mixing temperatures. However, its high aromatic content allows it to evaporate quickly during the mixing procedures. The RTFO mass loss was determined to be as high as $1.92 \%$ for RA1.

RA2 is a semisolid black substance with an asphalt odor. This product is manufactured by rerefining used oils through vacuum distillation. Using a rerefined product as the rejuvenator is a step toward enhancing the use of recycled material. This rejuvenator has a high flash point of $522^{\circ} \mathrm{F}\left(272^{\circ} \mathrm{C}\right)$ and does not release much smoke at high temperatures. It also evaporates much less than RAl at mixing temperatures, and its RTFO mass loss is only $0.21 \%$.

2.3. Sample Preparation. Sixteen samples were prepared by varying the RAP content and the type of RAP, virgin binder, and recycling agent. The two virgin binders were used as controls. The samples were prepared by mixing a soft binder with the RAP binder. The soft binder is a mixture of a virgin binder and a recycling agent. This sequence is consistent with the practice that is often followed by the industry. Similar initial high PG values were required to facilitate the comparison between samples. Thus, the target grade for the samples was set similar to the high PG of virgin binders $\pm 1^{\circ} \mathrm{C}$. To determine the proportion of the components that would produce samples with those target grades, the following three steps were followed.
2.3.1. Step 1: Determination of Soft Binder Grade. The first step was to determine the grade of the soft binder in such a way that, after blending with the RAP binder, a sample with the target grade is achieved. For this purpose, a linear interpolation was used to estimate the grade of the soft binder, along with the RAP content, the high PG of the RAP, and the target high PG. This is in accordance with the method recommended in ASTM D4887. Figure 1 shows this interpolation for each combination of virgin and RAP binder.

2.3.2. Step 2: Establishing Softening Curves. Softening curves were established for each combination of virgin binder and recycling agent, as shown in Figure 2. The dotted lines represent the linear trend lines. The softening power of the RA2 was considerably lower than the RA1. Therefore, large doses were needed to soften the binder to the desired grade. This fact makes RA2 an inappropriate choice when the high RAP content is considered, especially when the RAP is highly aged.

2.3.3. Step 3: Calculating the Proportion of Material. The results from the two preceding steps made it possible to calculate the proportion of the RAP binder, virgin binder, and recycling agent for each sample. Table 2 presents the factorial design of samples and the composition of each. Figure 3 is a flowchart that shows the steps for the sample preparation process.

\section{Results and Discussions}

3.1. RTFO Aging. The RTFO simulates the aging that the binder undergoes during construction. This aging is primarily due to the evaporation of lighter components of the asphalt binder when it is heated. Table 3 shows the results of the DSR tests and the high PG of the samples before and after RTFO aging and the resulting high PG values. The high PG values for nonaged and RTFO-aged samples were determined differently based on the corresponding criteria (formulas (1) and (2)).

$$
\begin{array}{r}
\text { Original (nonaged) sample: } \frac{G^{*}}{\sin \delta} \geq 1.0 \mathrm{kPa} \\
\text { RTFO-aged sample: } \frac{G^{*}}{\sin \delta} \geq 2.2 \mathrm{kPa} .
\end{array}
$$

The results showed that the degree of aging caused by the RTFO depended on the type of asphalt and recycling agent. VB1 lost more weight in the RTFO $(0.61 \%$ compared to $0.43 \%$ for VB2) and experienced more aging. Its RTFO grade (based on formula (2)) was $0.77^{\circ} \mathrm{C}$ higher than its nonaged grade (based on formula (1)). On the other hand, the RTFO grade was $0.79^{\circ} \mathrm{C}$ less than the nonaged grade for VB2. Generally, RA1 increased the RTFO aging, while RA2 did not influence it significantly. There is a meaningful correlation between the percentage of RA1 and the extent of RTFO aging (see the correlation in Figure 4). This was expectable, because RA1 has a high aromatic content and RTFO mass loss. Faster RTFO aging is not necessarily a negative quality. In fact, PG 

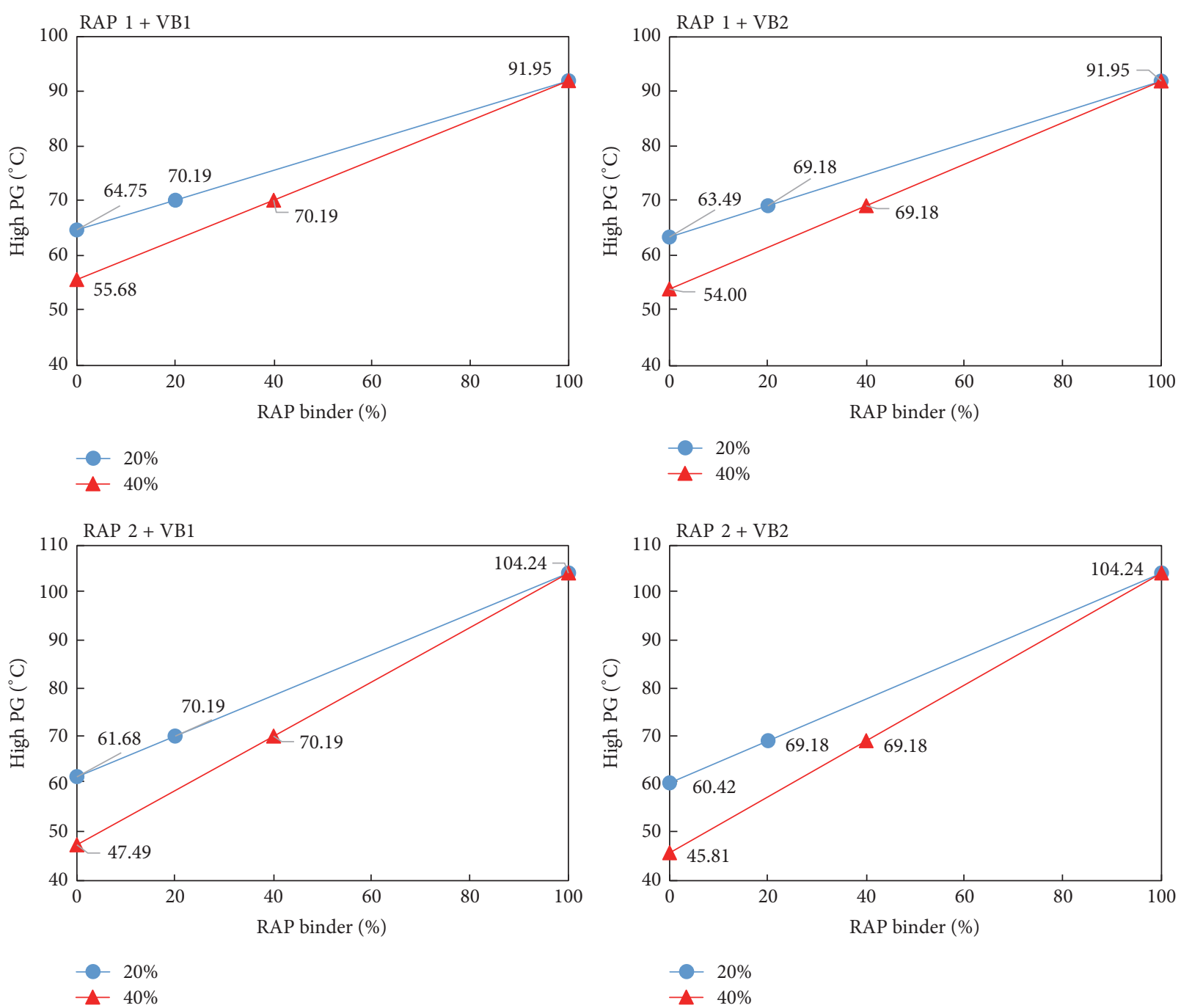

FIGURE 1: Soft binder grade determination.
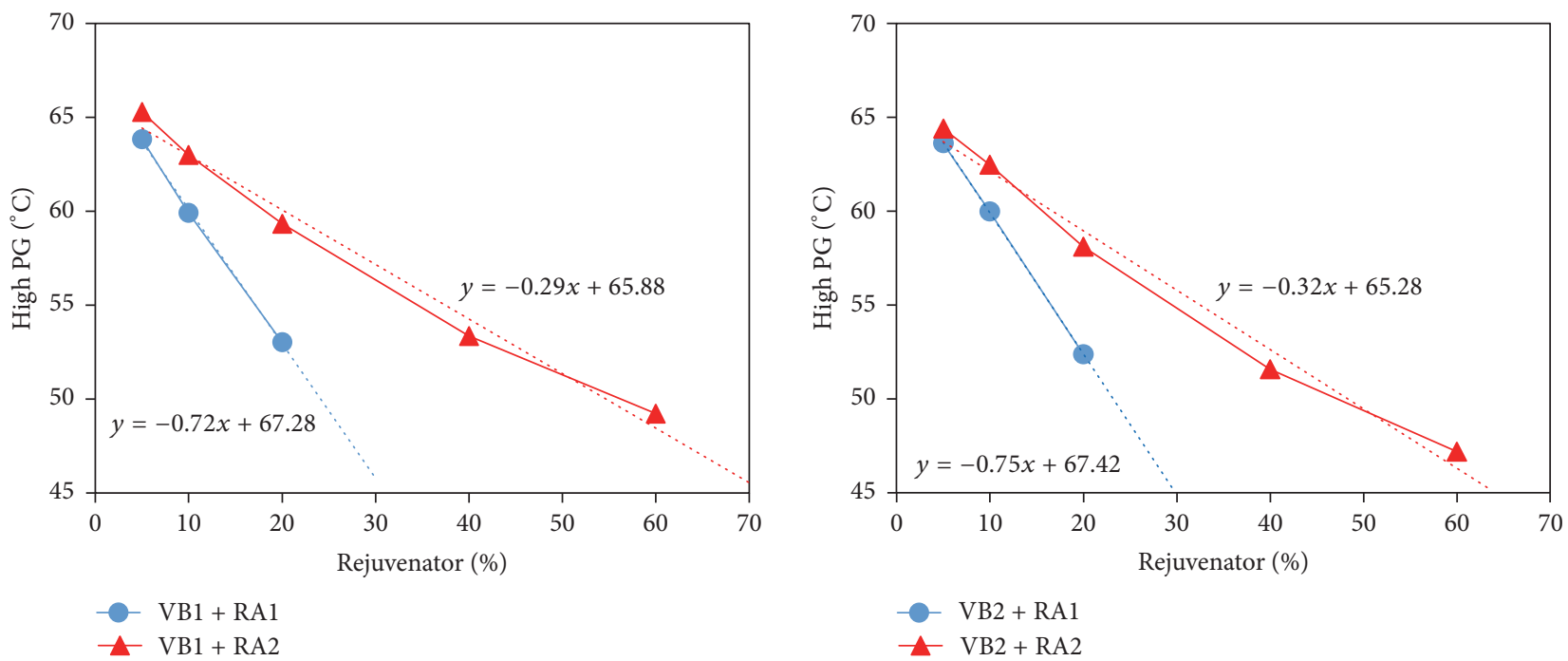

FIGURE 2: Softening curves. 
TABLE 2: Factorial design and composition of samples.

\begin{tabular}{|c|c|c|c|c|c|c|c|c|c|}
\hline \multirow{2}{*}{ Sample number } & \multicolumn{6}{|c|}{ Sample composition } & \multirow{2}{*}{ Target high PG $\left({ }^{\circ} \mathrm{C}\right)$} & \multirow{2}{*}{ Soft binder high PG $\left({ }^{\circ} \mathrm{C}\right)$} & \multirow{2}{*}{$\mathrm{RA} / \mathrm{VB}(\%)$} \\
\hline & VB & RA & RAP & VB\% & $\mathrm{RA} \%$ & $\%$ RAP & & & \\
\hline S01 & \multirow{8}{*}{ VB1 } & \multirow{4}{*}{ RA1 } & \multirow{2}{*}{ RAP1 } & 76.6 & 3.4 & 20 & $70.19 \pm 1$ & 64.75 & 4.3 \\
\hline S02 & & & & 50.3 & 9.7 & 40 & $70.19 \pm 1$ & 55.68 & 16.1 \\
\hline S03 & & & \multirow{2}{*}{ RAP2 } & 73.8 & 6.2 & 20 & $70.19 \pm 1$ & 61.68 & 7.7 \\
\hline S04 & & & & 43.2 & 16.8 & 40 & $70.19 \pm 1$ & 47.49 & 28.0 \\
\hline S05 & & \multirow{4}{*}{ RA2 } & \multirow{2}{*}{ RAP1 } & 75.1 & 4.9 & 20 & $70.19 \pm 1$ & 64.75 & 6.2 \\
\hline S06 & & & & 40.7 & 19.3 & 40 & $70.19 \pm 1$ & 55.68 & 32.2 \\
\hline S07 & & & \multirow{2}{*}{ RAP2 } & 69.1 & 10.9 & 20 & $70.19 \pm 1$ & 61.68 & 13.6 \\
\hline S08 & & & & 19.8 & 40.2 & 40 & $70.19 \pm 1$ & 47.49 & 67.0 \\
\hline S09 & \multirow{8}{*}{ VB2 } & \multirow{4}{*}{ RA1 } & \multirow{2}{*}{ RAP1 } & 75.9 & 4.1 & 20 & $69.18 \pm 1$ & 63.49 & 5.2 \\
\hline S10 & & & & 49.3 & 10.7 & 40 & $69.18 \pm 1$ & 54.00 & 17.9 \\
\hline S11 & & & \multirow{2}{*}{ RAP2 } & 72.5 & 7.5 & 20 & $69.18 \pm 1$ & 60.42 & 9.4 \\
\hline S12 & & & & 42.8 & 17.2 & 40 & $69.18 \pm 1$ & 45.81 & 28.6 \\
\hline S13 & & \multirow{4}{*}{ RA2 } & \multirow{2}{*}{ RAP1 } & 74.1 & 5.9 & 20 & $69.18 \pm 1$ & 63.49 & 7.4 \\
\hline S14 & & & & 40.5 & 19.5 & 40 & $69.18 \pm 1$ & 54.00 & 32.6 \\
\hline S15 & & & \multirow{2}{*}{ RAP2 } & 68.2 & 11.8 & 20 & $69.18 \pm 1$ & 61.42 & 14.7 \\
\hline S16 & & & & 20.2 & 39.8 & 40 & $69.18 \pm 1$ & 45.81 & 66.3 \\
\hline
\end{tabular}

Determine the true high-temperature PG for the virgin asphalt

Recover the RAP binder from the RAP mix and determine the true high-temperature PG for it

Calculate the PG of the soft binder in a way that the high PG of the blended binder becomes similar to that of the reference virgin asphalt (using the procedure described in ASTM D4887)

Establish a softening curve for each combination of virgin asphalt and rejuvenator. Determine the rejuvenator dosage that yields a soft binder with the high PG that was calculated in the previous step

Prepare the rejuvenated samples with blending appropriate proportions of RAP binder, virgin asphalt, and rejuvenator and determine the true high-temperature PG of samples

FIgURE 3: The flowchart for the sample preparation process.

specifications call for a minimum stiffness for the pavement to have the adequate strength after construction. However, if a rejuvenator causes faster aging, this should be known and considered during the mix design phase.

The phase angle is relatively small for samples with a large dosage of RA2. For instance, samples 12 and 16 have almost similar magnitudes of $G^{*} / \sin \delta$, but the phase angle is $8^{\circ}$ smaller for sample 16 . Therefore, RA2 decreases the viscous portion of the complex modulus.

3.2. PAV Aging. Three 20-hour cycles of the PAV aging with a temperature of $100^{\circ} \mathrm{C}$ and a pressure of $2.1 \mathrm{MPa}$ were applied. Table 4 displays the results from the DSR tests on samples after each PAV cycle. These samples were already RTFOaged. Therefore, the criterion for the RTFO samples (formula (2)) was used to determine their high PG. DSR testing on samples 8 and 16 after 60 hours of aging did not result in valid data. Large complex modulus values were measured during the first few iterations, but the measurements dropped rapidly and finally converged to very low values. In some cases, the target strain of $10 \%$ was not achieved with the maximum stress that the DSR could apply. These samples also exhibited unusual physical behavior. Although the samples are expected to be extremely hard after 60 hours of aging, they could be easily cut off by a spatula in a brittle manner at room temperature. This is an indication of weak cohesion and shear and tensile strengths of the binder. These samples had very low values of $\delta$ even after the first PAV cycle. This infers that they have a less viscous behavior when compared to conventional asphalt binders.

Table 5 summarizes the results of the PAV aging experiment and shows the increase in the high PG that takes place in each stage. Critical PAV time values are also presented. The critical PAV time was calculated for samples as a measure of durability. This parameter is defined as the PAV aging time it takes to increase the high PG from $70^{\circ} \mathrm{C}$ to $95^{\circ} \mathrm{C}$. PAV times 
TABLE 3: High PG of samples based on nonaged and RTFO-aged criteria.

\begin{tabular}{|c|c|c|c|c|c|c|c|c|c|c|}
\hline \multirow[b]{2}{*}{ Sample } & \multirow[b]{2}{*}{ Total RA\% } & \multicolumn{4}{|c|}{ No aging } & \multicolumn{4}{|c|}{ RTFO } & \multirow{2}{*}{$\begin{array}{l}\text { Difference } \\
\text { (RTFO-no } \\
\text { aging) }\left({ }^{\circ} \mathrm{C}\right)\end{array}$} \\
\hline & & Temp. $\left({ }^{\circ} \mathrm{C}\right)$ & $\delta\left(^{\circ}\right)$ & $\begin{array}{c}G^{*} / \sin \delta \\
(\mathrm{kPa})\end{array}$ & $\begin{array}{l}\text { High PG } \\
\quad\left({ }^{\circ} \mathrm{C}\right)\end{array}$ & Temp. $\left({ }^{\circ} \mathrm{C}\right)$ & $\delta\left(^{\circ}\right)$ & $\begin{array}{c}G^{*} / \sin \delta \\
(\mathrm{kPa})\end{array}$ & $\begin{array}{l}\text { High PG } \\
\quad\left({ }^{\circ} \mathrm{C}\right)\end{array}$ & \\
\hline \multirow[t]{2}{*}{ VB1 } & \multirow[t]{2}{*}{0} & 67 & 86 & 1.48 & \multirow{2}{*}{70.19} & 67 & 83 & 3.68 & \multirow{2}{*}{70.97} & \multirow{2}{*}{0.77} \\
\hline & & 76 & 86 & 0.49 & & 73 & 85 & 1.69 & & \\
\hline \multirow[t]{2}{*}{ S01 } & \multirow{2}{*}{3.42} & 67 & 86 & 1.35 & \multirow{2}{*}{69.47} & 67 & 82 & 3.19 & \multirow{2}{*}{70.17} & \multirow{2}{*}{0.70} \\
\hline & & 73 & 87 & 0.65 & & 73 & 84 & 1.58 & & \\
\hline \multirow[t]{2}{*}{ S02 } & \multirow{2}{*}{9.68} & 67 & 85 & 1.46 & \multirow{2}{*}{69.97} & 67 & 80 & 4.08 & \multirow{2}{*}{71.88} & \multirow{2}{*}{1.91} \\
\hline & & 73 & 87 & 0.68 & & 73 & 83 & 1.91 & & \\
\hline \multirow[t]{2}{*}{ S03 } & \multirow{2}{*}{6.19} & 67 & 85 & 1.62 & \multirow{2}{*}{70.96} & 67 & 82 & 4.25 & \multirow{2}{*}{72.10} & \multirow{2}{*}{1.14} \\
\hline & & 73 & 87 & 0.78 & & 73 & 84 & 1.96 & & \\
\hline S04 & 16.82 & 67 & 84 & 1.53 & 70.72 & 67 & 79 & 4.88 & 73.58 & 2.86 \\
\hline & & 73 & 86 & 0.77 & & 73 & 82 & 2.36 & & \\
\hline S05 & 4.93 & 67 & 85 & 1.46 & 7055 & 67 & 80 & 3.79 & 71.32 & 0.77 \\
\hline & & 73 & 86 & 0.77 & & 73 & 82 & 1.78 & & \\
\hline S06 & 19.33 & 67 & 83 & 1.35 & 69.74 & 67 & 67 & 3.31 & 70.65 & 0.90 \\
\hline & & 73 & 85 & 0.70 & & 73 & 73 & 1.69 & & \\
\hline S07 & 10.48 & 67 & 84 & 1.61 & 70.87 & 67 & 79 & 3.80 & 7192 & 104 \\
\hline & & 73 & 86 & 0.77 & & 73 & 82 & 1.95 & & \\
\hline S08 & 40.18 & 67 & 74 & 1.42 & 70.59 & 67 & 69 & 3.34 & 70.65 & 0.06 \\
\hline & & 73 & 75 & 0.79 & & 73 & 72 & 1.68 & & \\
\hline VB2 & 0 & 67 & 88 & 1.29 & 69.18 & 67 & 85 & 2.62 & 68.39 & -0.79 \\
\hline & & 76 & 88 & 0.45 & & 73 & 87 & 1.23 & & \\
\hline S09 & 4.14 & 67 & 86 & 1.42 & 69.96 & 67 & 84 & 2.98 & 6937 & -0.59 \\
\hline & & 73 & 87 & 0.70 & & 73 & 85 & 1.38 & & \\
\hline S10 & 10.73 & 67 & 86 & 1.26 & 69.04 & 67 & 83 & 2.97 & 69.42 & 0.38 \\
\hline & & 73 & 87 & 0.63 & & 73 & 84 & 1.41 & & \\
\hline S11 & 7.53 & 67 & 86 & 1.34 & 69.36 & 67 & 84 & 2.92 & 69.33 & -0.02 \\
\hline & & 73 & 88 & 0.64 & & 73 & 86 & 1.41 & & \\
\hline S12 & 17.18 & 67 & 85 & 1.43 & 7007 & 67 & 81 & 3.42 & 70.63 & 0.56 \\
\hline & & 73 & 87 & 0.71 & & 73 & 84 & 1.65 & & \\
\hline $\mathrm{S} 13$ & 5.88 & 67 & 84 & 1.15 & 68.29 & 67 & 82 & 2.52 & 68.09 & -0.20 \\
\hline & & 73 & 85 & 0.60 & & 73 & 84 & 1.19 & & \\
\hline S14 & 1954 & 67 & 82 & 1.36 & 6955 & 67 & 79 & 2.70 & 6861 & -0.94 \\
\hline & & 73 & 84 & 0.66 & & 73 & 81 & 1.26 & & \\
\hline S15 & 11.75 & 67 & 85 & 1.38 & 69.85 & 67 & 82 & 2.85 & 69.16 & -0.69 \\
\hline & & 73 & 86 & 0.70 & & 73 & 84 & 1.39 & & \\
\hline S16 & 39.79 & 67 & 77 & 1.44 & 70.00 & 67 & 74 & 2.74 & 68.90 & -1.10 \\
\hline & & 73 & 80 & 0.69 & & 73 & 77 & 1.37 & & \\
\hline
\end{tabular}

corresponding to high PGs of $70^{\circ} \mathrm{C}$ and $95^{\circ} \mathrm{C}$ were obtained by interpolation or extrapolation of the results.

As a general trend, RA1 caused slower aging of the binders, while RA2 accelerated the aging. A meaningful correlation existed between increasing the dosage of RAl and the critical PAV time. Also, there was a reverse correlation between the dosage of RA2 and the critical PAV time (see Figure 5). The type of virgin binder also had a significant 


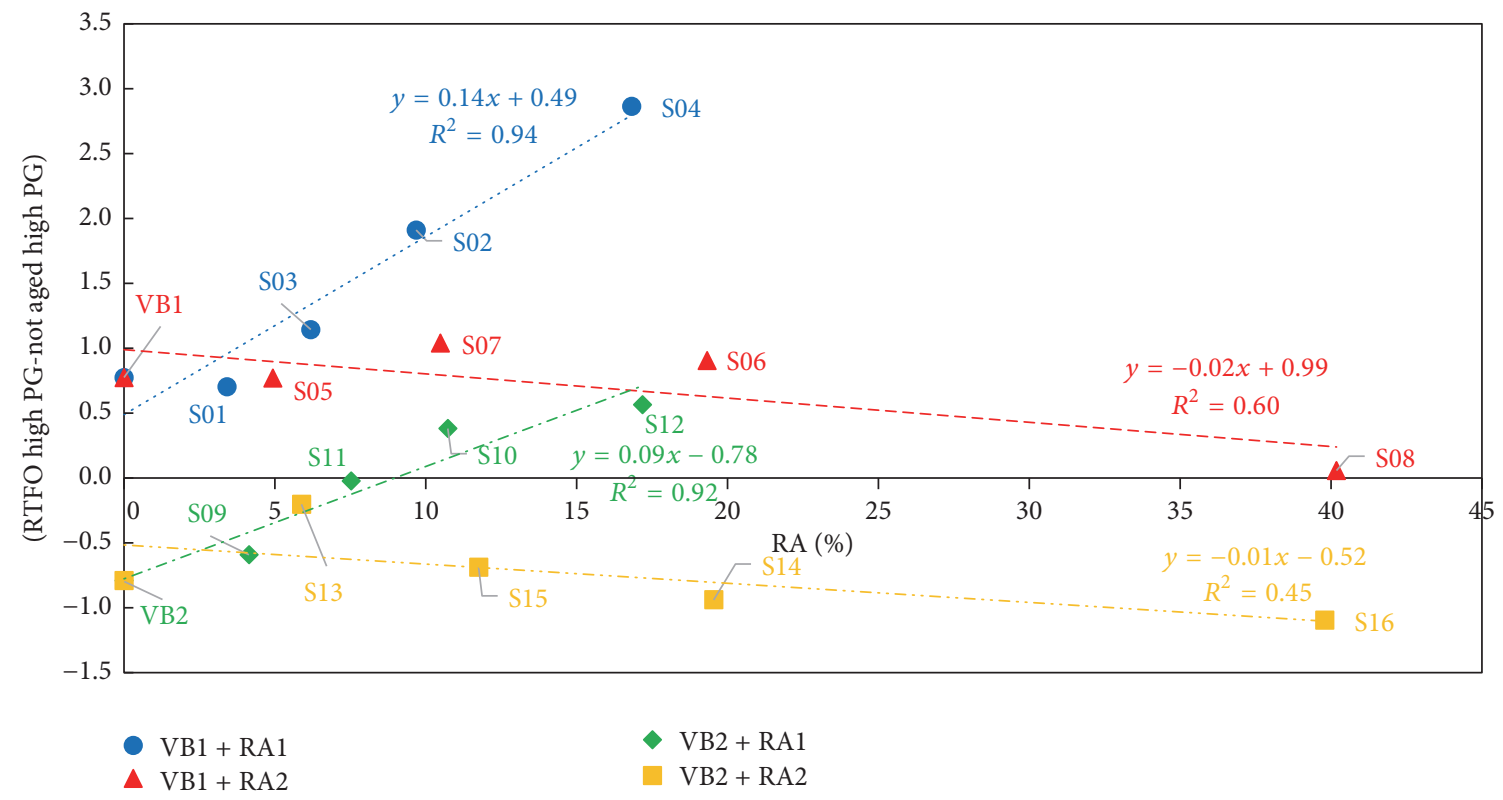

Figure 4: Change in the high PG by RTFO (RTFO PG, not aged PG).

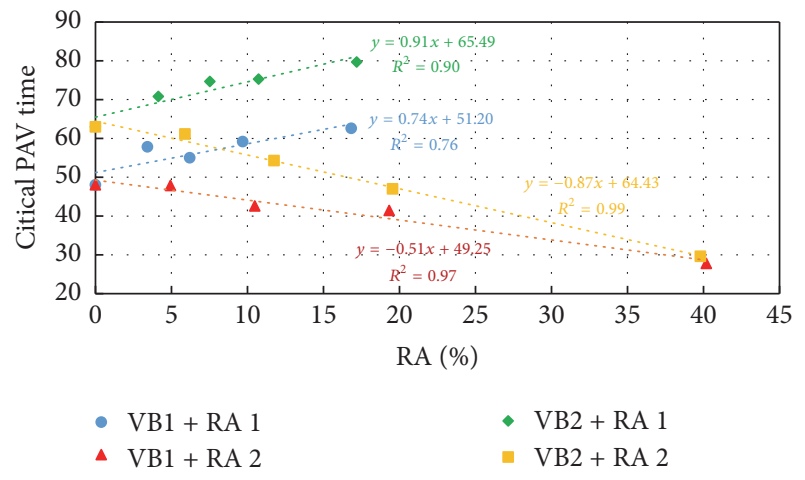

FIGURE 5: Variations of critical PAV time with rejuvenator content.

influence on the rate of aging and the critical PAV time. VB1 aged faster than VB2, and its aging was more influenced by rejuvenators.

The rate of aging decreased with the increase in PAV time. The first cycles increased the high PG by an average of $12^{\circ} \mathrm{C}$. This increase was, respectively, $9^{\circ} \mathrm{C}$ and $6^{\circ} \mathrm{C}$ for the second and third cycles. Figure 6 shows the increase in high PG for each sample in each stage of aging.

A 20-hour cycle of PAV simulates almost 8 years of field aging [17]. Therefore, to estimate pavement service life (the service time before excessive binder aging), every hour of PAV aging time was assumed to correspond to 0.4 years of field aging. Based on this assumption, the field longevity of binders was estimated, as illustrated in Figure 7. The right vertical axis in this figure indicates service life.

Samples 8 and 16, which contained large quantities of RA2, aged extremely fast. Their aging after 40 hours was more

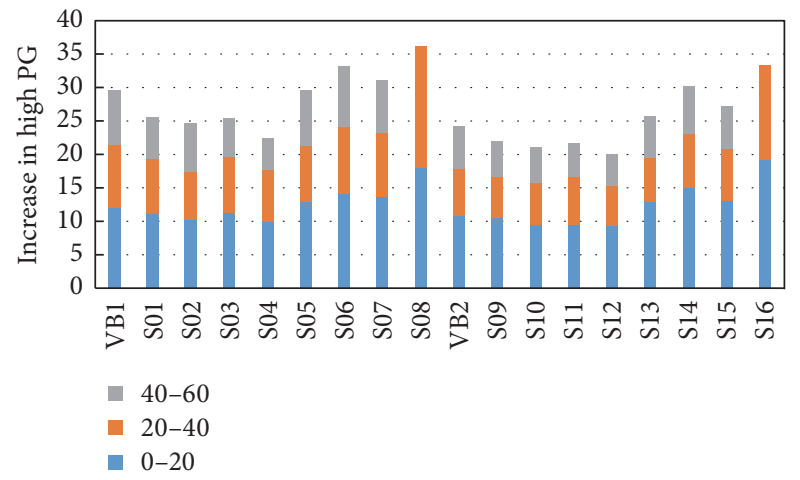

FIgUre 6: Rise of high PG in each stage of PAV aging.

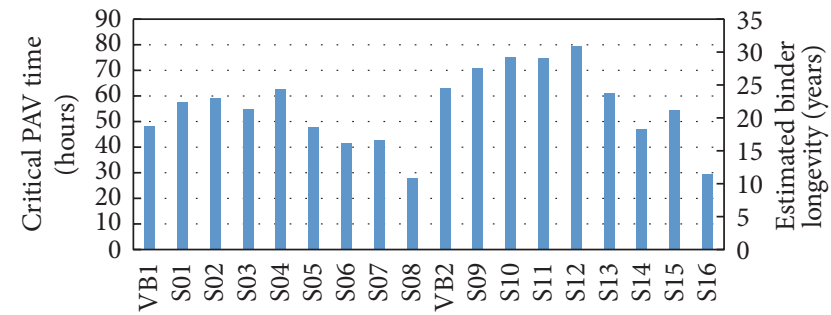

FIGURE 7: Critical PAV time (left axis) and estimated longevity (right axis) of samples.

than that of any other sample after 60 hours. Also, relatively small phase angles were obtained.

3.3. BBR Tests. The BBR test evaluates an asphalt binder's low-temperature cracking resistance. The stiffness is obtained by applying a point load on a small asphalt beam and 
TABLE 4: DSR tests results for PAV-aged samples.

\begin{tabular}{|c|c|c|c|c|c|c|c|c|c|c|c|c|}
\hline \multirow[b]{2}{*}{ Sample } & \multicolumn{4}{|c|}{ 20-hour PAV } & \multicolumn{4}{|c|}{ 40-hour PAV } & \multicolumn{4}{|c|}{ 60-hour PAV } \\
\hline & $\begin{array}{c}\text { Temp. } \\
\left({ }^{\circ} \mathrm{C}\right)\end{array}$ & $\delta\left(^{\circ}\right)$ & $\begin{array}{c}G^{*} / \sin \delta \\
(\mathrm{kPa})\end{array}$ & $\begin{array}{c}\text { High PG } \\
\left({ }^{\circ} \mathrm{C}\right)\end{array}$ & $\begin{array}{c}\text { Temp. } \\
\left({ }^{\circ} \mathrm{C}\right)\end{array}$ & $\delta\left(^{\circ}\right)$ & $\begin{array}{c}G^{*} / \sin \delta \\
(\mathrm{kPa})\end{array}$ & $\begin{array}{c}\text { High PG } \\
\left({ }^{\circ} \mathrm{C}\right)\end{array}$ & $\begin{array}{c}\text { Temp. } \\
\left({ }^{\circ} \mathrm{C}\right)\end{array}$ & $\delta\left(^{\circ}\right)$ & $\begin{array}{c}G^{*} / \sin \delta \\
(\mathrm{kPa})\end{array}$ & $\begin{array}{c}\text { High PG } \\
\left({ }^{\circ} \mathrm{C}\right)\end{array}$ \\
\hline \multirow{2}{*}{ VB1 } & 82 & 78 & 2.51 & \multirow{2}{*}{83.05} & 82 & 74 & 8.47 & \multirow{2}{*}{92.36} & 82 & 66 & 22.79 & \multirow{2}{*}{100.53} \\
\hline & 88 & 81 & 1.18 & & 88 & 78 & 3.88 & & 88 & 70 & 10.69 & \\
\hline \multirow{2}{*}{ S01 } & 76 & 78 & 4.31 & \multirow{2}{*}{81.39} & 82 & 76 & 5.35 & \multirow{2}{*}{89.51} & 82 & 69 & 13.79 & \multirow{2}{*}{95.78} \\
\hline & 82 & 81 & 2.04 & & 88 & 79 & 2.63 & & 88 & 73 & 6.2 & \\
\hline \multirow{2}{*}{ S02 } & 82 & 81 & 2.22 & \multirow{2}{*}{82.07} & 82 & 75 & 5.54 & \multirow{2}{*}{89.36} & 82 & 69 & 11.28 & \multirow{2}{*}{96.63} \\
\hline & 88 & 83 & 1.03 & & 88 & 78 & 2.61 & & 88 & 73 & 5.77 & \\
\hline \multirow{2}{*}{ S03 } & 82 & 80 & 2.60 & \multirow{2}{*}{83.43} & 82 & 73 & 7.00 & \multirow{2}{*}{91.78} & 82 & 69 & 14.82 & \multirow{2}{*}{97.46} \\
\hline & 88 & 83 & 1.29 & & 88 & 77 & 3.44 & & 88 & 73 & 7.07 & \\
\hline \multirow{2}{*}{ S04 } & 82 & 79 & 2.80 & \multirow{2}{*}{83.50} & 82 & 73 & 6.64 & \multirow{2}{*}{91.36} & 82 & 69 & 13.31 & \multirow{2}{*}{96.08} \\
\hline & 88 & 82 & 1.36 & & 88 & 77 & 3.27 & & 88 & 73 & 6.18 & \\
\hline S05 & 82 & 79 & 2.84 & 84.28 & 82 & 71 & 8.64 & 92.59 & 82 & 64 & 23.20 & 100.87 \\
\hline sob & 88 & 81 & 1.45 & 84.28 & 88 & 75 & 3.98 & 92.59 & 88 & 68 & 10.97 & $100.8 \%$ \\
\hline S06 & 82 & 75 & 3.05 & & 82 & 66 & 10.66 & 94.77 & 82 & 59 & 30.65 & 103.73 \\
\hline 506 & 88 & 78 & 1.50 & 84.77 & 88 & 70 & 5.08 & 94.17 & 88 & 62 & 14.81 & 103.13 \\
\hline $\mathrm{S} 07$ & 82 & 77 & 3.40 & 85.58 & 82 & 68 & 11.25 & 95.07 & 82 & 62 & 26.36 & 102.99 \\
\hline 507 & 88 & 80 & 1.64 & 85.58 & 88 & 72 & 5.32 & प्र5.0/ & 88 & 66 & 12.96 & 102.99 \\
\hline S08 & 82 & 74 & 4.27 & 8857 & 82 & 68 & 9.50 & 10682 & & Iny & id data & \\
\hline & 88 & 74 & 2.33 & $88.5 /$ & 88 & 68 & 6.67 & 106.82 & & & & \\
\hline VB2 & 76 & 82 & 3.65 & 7986 & 82 & 81 & 3.82 & 8676 & 82 & 74 & 9.67 & 9312 \\
\hline & 82 & 85 & 1.66 & & 88 & 83 & 1.91 & & 88 & 78 & 4.35 & \\
\hline S09 & 76 & 81 & 3.72 & 8028 & 82 & 80 & 3.83 & 86.47 & 82 & 76 & 7.36 & 91.80 \\
\hline & 82 & 84 & 1.78 & & 88 & 82 & 1.82 & 00.47 & 88 & 80 & 3.51 & $\$ 1.00$ \\
\hline S10 & 76 & 81 & 3.20 & 7889 & 82 & 80 & 3.19 & 85.20 & 82 & 75 & 6.68 & 90.57 \\
\hline & 82 & 83 & 1.47 & 18.89 & 88 & 83 & 1.59 & 85.20 & 88 & 78 & 3.07 & 90.31 \\
\hline S11 & 76 & 80 & 3.79 & 78.82 & 82 & 80 & 3.59 & 85.93 & 82 & 75 & 7.03 & 90.96 \\
\hline S11 & 82 & 83 & 1.19 & 18.82 & 88 & 81 & 1.70 & 85.93 & 88 & 79 & 3.23 & 90.90 \\
\hline $\mathrm{S} 12$ & 76 & 79 & 3.56 & 79.97 & 82 & 78 & 3.55 & 86.03 & 82 & 75 & 6.98 & 90.71 \\
\hline $\mathrm{S} 12$ & 82 & 82 & 1.72 & 79.97 & 88 & 81 & 1.74 & 86.03 & 88 & 78 & 3.15 & 90.71 \\
\hline $\mathrm{S} 13$ & 76 & 76 & 4.15 & & 82 & 75 & 4.35 & & 82 & 71 & 9.00 & \\
\hline S13 & 82 & 80 & 1.96 & 81.08 & 88 & 79 & 2.09 & 87.58 & 88 & 75 & 4.38 & 93.74 \\
\hline S14 & 82 & 74 & 2.71 & 83.70 & 82 & 67 & 7.57 & 91.86 & 82 & 61 & 17.34 & 98.95 \\
\hline $\mathrm{S} 14$ & 88 & 77 & 1.30 & 83.70 & 88 & 72 & 3.57 & 91.86 & 88 & 66 & 8.35 & 98.95 \\
\hline S15 & 82 & 80 & 2.27 & 82.28 & 82 & 71 & 5.83 & 89.97 & 82 & 69 & 12.91 & 96.41 \\
\hline S13 & 88 & 82 & 1.15 & 82.28 & 88 & 76 & 2.80 & 89.91 & 88 & 72 & 6.18 & 96.41 \\
\hline S16 & 82 & 66 & 4.20 & 8730 & 82 & 62 & 8.58 & 10149 & & & & \\
\hline & 88 & 69 & 2.02 & & 88 & 63 & 5.64 & & & & & \\
\hline
\end{tabular}

measuring the deflection at $8,15,30,60,120$, and 240 seconds. The output of the BBR consists of two parameters:

(i) Creep stiffness (S), which is a measure of thermal stresses in the asphalt due to contraction.

(ii) The $m$-value, which is the slope of the creep stiffness master curve and indicates the ability of the asphalt to relieve stresses through plastic deformation.

The BBR test was performed on all samples after the standard (20 hours) and the ultimate (60 hours) PAV aging. The results are presented in Table 6 . The PG system specifies the following requirement at 60 seconds and at the temperature $10^{\circ} \mathrm{C}$ higher than the low-temperature specification. This is based on the time-temperature superposition principle that allows shortening the loading time by increasing the temperature. For a PG 67-22 binder, these requirements should be met at $-12^{\circ} \mathrm{C}$ for a 20 -hour PAV-aged residue.

$$
S \leq 300 \mathrm{MPa}
$$

$m$-value $\geq 0.300$. 
TABLE 5: The increase in high PG of samples after each level of aging and resulting critical PAV time.

\begin{tabular}{|c|c|c|c|c|c|c|c|c|c|}
\hline \multirow[b]{2}{*}{ Sample } & \multicolumn{5}{|c|}{ High PG $\left({ }^{\circ} \mathrm{C}\right)$} & \multicolumn{3}{|c|}{ Increase in high PG $\left({ }^{\circ} \mathrm{C}\right)$} & \multirow{2}{*}{$\begin{array}{l}\text { Critical } \\
\text { PAV time } \\
\text { (hours) }\end{array}$} \\
\hline & Not aged & $\begin{array}{c}\text { RTFO } \\
\text { aged }\end{array}$ & $\begin{array}{l}\text { 20-hour } \\
\text { PAV }\end{array}$ & $\begin{array}{l}\text { 40-hour } \\
\text { PAV }\end{array}$ & $\begin{array}{l}\text { 60-hour } \\
\text { PAV }\end{array}$ & $0-20$ hours & 20-40 hours & $\begin{array}{l}40-60 \\
\text { hours }\end{array}$ & \\
\hline VB1 & 70.19 & 70.97 & 83.05 & 92.36 & 100.53 & 12.08 & 9.31 & 8.17 & 48.07 \\
\hline S01 & 69.47 & 70.17 & 81.39 & 89.51 & 95.78 & 11.22 & 8.11 & 6.27 & 57.83 \\
\hline S02 & 69.97 & 71.88 & 82.07 & 89.36 & 96.63 & 10.19 & 7.29 & 7.27 & 59.21 \\
\hline S03 & 70.96 & 72.10 & 83.43 & 91.78 & 97.46 & 11.33 & 8.35 & 5.69 & 55.04 \\
\hline S04 & 70.72 & 73.58 & 83.50 & 91.36 & 96.08 & 9.92 & 7.86 & 4.72 & 62.65 \\
\hline S05 & 70.55 & 71.32 & 84.28 & 92.59 & 100.87 & 12.96 & 8.31 & 8.28 & 47.86 \\
\hline S06 & 69.74 & 70.65 & 84.77 & 94.77 & 103.73 & 14.12 & 10.00 & 8.96 & 41.42 \\
\hline S07 & 70.87 & 71.92 & 85.58 & 95.07 & 102.99 & 13.67 & 9.49 & 7.91 & 42.62 \\
\hline S08 & 70.59 & 70.65 & 88.57 & 106.82 & - & 17.92 & 18.25 & - & 27.77 \\
\hline VB2 & 69.18 & 68.39 & 79.86 & 86.76 & 93.12 & 11.47 & 6.91 & 6.36 & 62.97 \\
\hline S09 & 69.96 & 69.37 & 80.28 & 86.47 & 91.80 & 10.91 & 6.19 & 5.33 & 70.84 \\
\hline $\mathrm{S} 10$ & 69.04 & 69.42 & 78.89 & 85.20 & 90.57 & 9.47 & 6.32 & 5.37 & 75.29 \\
\hline S11 & 69.36 & 69.33 & 78.82 & 85.93 & 90.96 & 9.48 & 7.11 & 5.03 & 74.66 \\
\hline S12 & 70.07 & 70.63 & 79.97 & 86.03 & 90.71 & 9.34 & 6.06 & 5.72 & 79.68 \\
\hline S13 & 68.29 & 68.09 & 81.08 & 87.58 & 93.74 & 12.99 & 6.50 & 6.16 & 61.16 \\
\hline S14 & 69.55 & 68.61 & 83.70 & 91.86 & 98.95 & 15.09 & 8.16 & 7.09 & 47.01 \\
\hline S15 & 69.85 & 69.16 & 82.28 & 89.97 & 96.41 & 13.11 & 7.69 & 6.44 & 54.32 \\
\hline S16 & 70.00 & 68.90 & 87.30 & 101.49 & - & 18.40 & 14.19 & - & 29.66 \\
\hline
\end{tabular}

For all samples, the $m$-value criterion was more critical and dominated the determination of the low temperate PG. Virgin binders did not meet the $m$-value requirement for PG 67-22, but they were very close to it (0.299 for VB1 and 0.291 for VB2). VB1 had a better low-temperature performance, compared to VB2. It had a smaller creep stiffness and a higher $m$-value, despite VBl's higher stiffness at high-temperature and greater high-temperature PG.

The samples with RA1 passed the criteria for PG 67-22. Samples with RA2, on the other hand, did not meet these criteria and yielded lower $m$-values. Generally, the addition of RA1 did not significantly change the creep stiffness. The RA2, however, caused a fast drop in the stiffness. The higher the dosage of RA2, the smaller the values of creep stiffness (Figure 8). A smaller amount of low-temperature creep stiffness shows that less thermal stresses are expected. However, the very small stiffness found in the samples that contain a large dosage of RA2 is an indication of the detrimental behavior of RA2 when applied at a large dosage.

The RA1 increased the $m$-value, and the RA2 decreased it. Therefore, samples with RA1 had a lower low-temperature PG. This effect was more significant when the RA content was higher (Figure 8). A higher $m$-value shows a binder with a more viscous behavior and a greater ability to relieve stresses. The less viscous behavior of samples containing RA2 is in line with the observations from DSR tests where these samples had lower phase angles.
Similar to the DSR experiment, samples 8 and 16 did not output valid data. The samples were very soft, and they broke under the BBR load at $-6^{\circ} \mathrm{C}$. Also, their results at $-12^{\circ}$ and $-18^{\circ} \mathrm{C}$ yielded critical temperature values that were out of acceptable ranges.

Applying the extended PAV aging (60 hours) increased the creep stiffness and decreased the $m$-value. The change in the $m$-value was more significant. While the creep stiffness critical temperature increased by $3^{\circ} \mathrm{C}$ on average, the average rise in the $m$-value critical temperature was $9^{\circ} \mathrm{C}$. Since the 60-hour aged samples were excessively hard, it was difficult to pour the BBR mold with these samples. Therefore, they were heated to $175^{\circ} \mathrm{C}$ for 10 minutes to achieve the required fluidness.

Unlike DSR tests, BBR tests on samples with extended PAV aging did not add important information about the effects of using RAP and rejuvenation. Therefore, performing BBR tests on samples with standard aging is adequate for durability evaluation.

\section{Conclusion}

This research evaluated the durability of recycled asphalt binders. For this purpose, two virgin binders and 16 samples containing RAP binder and rejuvenator were aged at four stages: one RTFO and three PAV cycles. The samples were different in the type of RAP binder, virgin binder, and recycling agent. The RAP contents of $20 \%$ and $40 \%$ were 
TABLE 6: BBR test for 20-hour PAV-aged samples.

\begin{tabular}{|c|c|c|c|c|c|c|c|c|c|}
\hline \multirow[b]{2}{*}{ Sample } & \multirow[b]{2}{*}{ RA\% } & \multirow[b]{2}{*}{ Temp. $\left({ }^{\circ} \mathrm{C}\right)$} & \multicolumn{3}{|c|}{ 20-hour PAV } & \multicolumn{3}{|c|}{ 60-hour PAV } & \multirow{2}{*}{$\begin{array}{l}\text { Low temp. PG } \\
\text { increase }\left({ }^{\circ} \mathrm{C}\right) \\
20 \text { to } 60 \text { hours }\end{array}$} \\
\hline & & & $S$ & $m$-value & $\begin{array}{c}\text { Low } \\
\text { temp. PG } \\
\left({ }^{\circ} \mathrm{C}\right)\end{array}$ & $S$ & $m$-value & $\begin{array}{c}\text { Low } \\
\text { temp. PG } \\
\left({ }^{\circ} \mathrm{C}\right)\end{array}$ & \\
\hline \multirow{3}{*}{ VB1 } & \multirow{3}{*}{0} & -6 & 161 & 0.362 & \multirow{3}{*}{-21.90} & 147 & 0.282 & \multirow{3}{*}{-14.48} & \multirow{3}{*}{7.43} \\
\hline & & -12 & 205 & 0.299 & & 235 & 0.211 & & \\
\hline & & -18 & 391 & 0.256 & & 448 & 0.178 & & \\
\hline \multirow{3}{*}{1} & \multirow{3}{*}{3.42} & -6 & 109 & 0.370 & \multirow{3}{*}{-23.37} & 159 & 0.292 & \multirow{3}{*}{-14.67} & \multirow{3}{*}{8.70} \\
\hline & & -12 & 191 & 0.313 & & 281 & 0.256 & & \\
\hline & & -18 & 367 & 0.267 & & 465 & 0.230 & & \\
\hline \multirow{3}{*}{2} & \multirow{3}{*}{9.68} & -6 & 78.7 & 0.377 & \multirow{3}{*}{-24.00} & 135 & 0.298 & \multirow{3}{*}{-15.74} & \multirow{3}{*}{8.26} \\
\hline & & -12 & 173 & 0.319 & & 248 & 0.251 & & \\
\hline & & -18 & 332 & 0.262 & & 480 & 0.182 & & \\
\hline \multirow{3}{*}{3} & & -6 & 116 & 0.358 & & 152 & 0.297 & & \\
\hline & 6.19 & -12 & 203 & 0.309 & -23.10 & 273 & 0.258 & -15.54 & 7.56 \\
\hline & & -18 & 388 & 0.253 & & 468 & 0.211 & & \\
\hline & & -6 & 90.4 & 0.364 & & 149 & 0.301 & & \\
\hline 4 & 16.82 & -12 & 194 & 0.314 & -23.68 & 269 & 0.266 & -16.17 & 7.51 \\
\hline & & -18 & 404 & 0.251 & & 461 & 0.232 & & \\
\hline & & -6 & 74.4 & 0.345 & & 126 & 0.273 & & \\
\hline 5 & 4.93 & -12 & 153 & 0.285 & -20.50 & 193 & 0.228 & -12.40 & 8.10 \\
\hline & & -18 & 282 & 0.255 & & 343 & 0.190 & & \\
\hline & & -6 & 39.6 & 0.340 & & 94.9 & 0.270 & & \\
\hline 6 & 19.33 & -12 & 91 & 0.267 & -19.29 & 144 & 0.234 & -11.00 & 8.29 \\
\hline & & -18 & 137 & 0.248 & & 212 & 0.202 & & \\
\hline & & -6 & 54.2 & 0.321 & & 108 & 0.268 & & \\
\hline 7 & 10.48 & -12 & 114 & 0.272 & -18.57 & 161 & 0.227 & -11.32 & 7.25 \\
\hline & & -18 & 193 & 0.246 & & 282 & 0.194 & & \\
\hline & & -6 & Invalid & Invalid & & Invalid & Invalid & & \\
\hline 8 & 40.18 & -12 & 34.1 & 0.241 & Invalid & 39.4 & 0.245 & Invalid & - \\
\hline & & -18 & 55.1 & 0.231 & & 61.3 & 0.230 & & \\
\hline & & -6 & 149 & 0.352 & & 184 & 0.276 & & \\
\hline VB2 & 0 & -12 & 301 & 0.291 & -21.11 & 341 & 0.215 & -13.64 & 7.48 \\
\hline & & -18 & 454 & 0.262 & & 487 & 0.183 & & \\
\hline & & -6 & 112 & 0.360 & & 182 & 0.294 & & \\
\hline 9 & 4.14 & -12 & 215 & 0.303 & -22.62 & 319 & 0.264 & -14.80 & 7.82 \\
\hline & & -18 & 393 & 0.274 & & 455 & 0.232 & & \\
\hline & & -6 & 83.6 & 0.365 & & 144 & 0.305 & & \\
\hline 10 & 10.73 & -12 & 180 & 0.327 & -24.84 & 267 & 0.270 & -16.86 & 7.98 \\
\hline & & -18 & 365 & 0.270 & & 445 & 0.239 & & \\
\hline & & -6 & 98.4 & 0.351 & & 173 & 0.298 & & \\
\hline 11 & 7.53 & -12 & 181 & 0.317 & -23.96 & 307 & 0.275 & -15.48 & 8.48 \\
\hline & & -18 & 387 & 0.265 & & 472 & 0.248 & & \\
\hline & & -6 & 85.4 & 0.373 & & 137 & 0.312 & & \\
\hline 12 & 17.18 & -12 & 175 & 0.329 & -25.63 & 261 & 0.274 & -17.89 & 7.73 \\
\hline & & -18 & 370 & 0.281 & & 470 & 0.246 & & \\
\hline
\end{tabular}


TABLE 6: Continued.

\begin{tabular}{|c|c|c|c|c|c|c|c|c|c|}
\hline \multirow[b]{2}{*}{ Sample } & \multirow[b]{2}{*}{ RA\% } & \multirow[b]{2}{*}{ Temp. $\left({ }^{\circ} \mathrm{C}\right)$} & \multicolumn{3}{|c|}{ 20-hour PAV } & \multicolumn{3}{|c|}{ 60-hour PAV } & \multirow[b]{2}{*}{$\begin{array}{l}\text { Low temp. PG } \\
\text { increase }\left({ }^{\circ} \mathrm{C}\right) \\
20 \text { to } 60 \text { hours }\end{array}$} \\
\hline & & & $S$ & $m$-value & $\begin{array}{c}\text { Low } \\
\text { temp. PG } \\
\left({ }^{\circ} \mathrm{C}\right)\end{array}$ & $S$ & $m$-value & $\begin{array}{c}\text { Low } \\
\text { temp. PG } \\
\left({ }^{\circ} \mathrm{C}\right)\end{array}$ & \\
\hline \multirow{3}{*}{13} & \multirow{3}{*}{5.88} & -6 & 76.3 & 0.346 & \multirow{3}{*}{-20.68} & 129 & 0.259 & \multirow{3}{*}{-10.98} & \multirow{3}{*}{9.70} \\
\hline & & -12 & 169 & 0.287 & & 264 & 0.210 & & \\
\hline & & -18 & 311 & 0.268 & & 358 & 0.191 & & \\
\hline \multirow{3}{*}{14} & \multirow{3}{*}{19.54} & -6 & 36.6 & 0.345 & \multirow{3}{*}{-21.19} & 77.9 & 0.256 & \multirow{3}{*}{-4.00} & \multirow{3}{*}{17.19} \\
\hline & & -12 & 74.8 & 0.293 & & 126 & 0.234 & & \\
\hline & & -18 & 135 & 0.260 & & 185 & 0.214 & & \\
\hline \multirow{3}{*}{15} & \multirow{3}{*}{11.75} & -6 & 51.2 & 0.329 & \multirow{3}{*}{-19.16} & 81.2 & 0.261 & \multirow{3}{*}{-9.31} & \multirow{3}{*}{9.85} \\
\hline & & -12 & 115 & 0.274 & & 193 & 0.226 & & \\
\hline & & -18 & 189 & 0.235 & & 277 & 0.197 & & \\
\hline \multirow{3}{*}{16} & \multirow{3}{*}{39.79} & -6 & Invalid & NA & \multirow{3}{*}{ Invalid } & 45.8 & 0.238 & \multirow{3}{*}{ Invalid } & \multirow{3}{*}{ Invalid } \\
\hline & & -12 & 37.5 & 0.271 & & 71.9 & 0.219 & & \\
\hline & & -18 & 47.5 & 0.266 & & 107 & 0.200 & & \\
\hline
\end{tabular}

used. The samples were prepared so that their initial high PG was similar to that of the virgin binder they contained. After each stage of aging, DSR tests were performed, and the hightemperature PG was determined. The following is a summary of findings obtained from the described experiment:

(1) The rejuvenators have a significant effect on the aging rate of the binder. A recycled binder can age either faster or slower than a virgin binder, depending on the rejuvenator that is used. In this experiment, RA1 caused slower aging, and RA2 caused faster aging. The higher the percentage of recycling agent, the greater its effect on the aging of the binder.

(2) The type and amount of rejuvenator can considerably affect the longevity of the binder. The use of a fastaging rejuvenator can reduce the life of the binder to less than one-half. Conversely, a slow aging rejuvenator can increase the life of the binder by up to $30 \%$.

(3) The extent of construction aging, which was simulated by the RTFO, is affected by the rejuvenator. A recycled binder containing a rejuvenator with a higher aromatic content is expected to undergo more aging due to construction heating.

(4) The effectiveness of RA2 for rejuvenating high RAP mixtures is questionable. This rejuvenator has relatively low softening power. Therefore, a large quantity of it is required to soften a binder with a high RAP content. In addition, binders containing a high volume of this recycling agent age very quickly and have a short life span before they become extensively aged again.

(5) RA1 has desirable properties for recycling high RAP mixtures. It has a high softening power, and a relatively small quantity is enough to rejuvenate a highly aged binder. Also, it has an advantageous aging behavior. It makes the binder age faster during construction and gives extra strength to the pavement immediately after construction when the strength is most needed. Afterwards, it decelerates aging and gives the binder a longer life span before excessive aging.

(6) The low-temperature behavior of recycled binders is significantly affected by the type and dosage of the rejuvenator. In this experiment, samples with RA1 had higher $m$-values, indicating their greater ability to relieve stresses. As a result, despite the virgin binder not passing the low-temperature criteria for PG 67-22, all RA1 samples did pass. Samples with the RA2, on the other hand, had smaller $m$-values. This correlates with the smaller viscous portion of the complex modulus, which was observed for RA2 samples in high-temperature DSR tests. It can be concluded from both DSR and BBR tests that RA2 causes a reduction in the viscous behavior of the binder.

(7) It is necessary to differentiate between rejuvenators that reduce the longevity of the binder and those that increase it. To achieve this, a quantitative description of durability is needed. Critical PAV time can serve as a measure of the longevity of the binder. Using this parameter to set a durability criterion for rejuvenation effectiveness is recommended.

\section{Conflicts of Interest}

The authors declare that there are no conflicts of interest regarding the publication of this paper.

\section{Acknowledgments}

This research was sponsored by the Florida Department of Transportation (FDOT). The authors express appreciation to the department for funding this effort. Special thanks are 

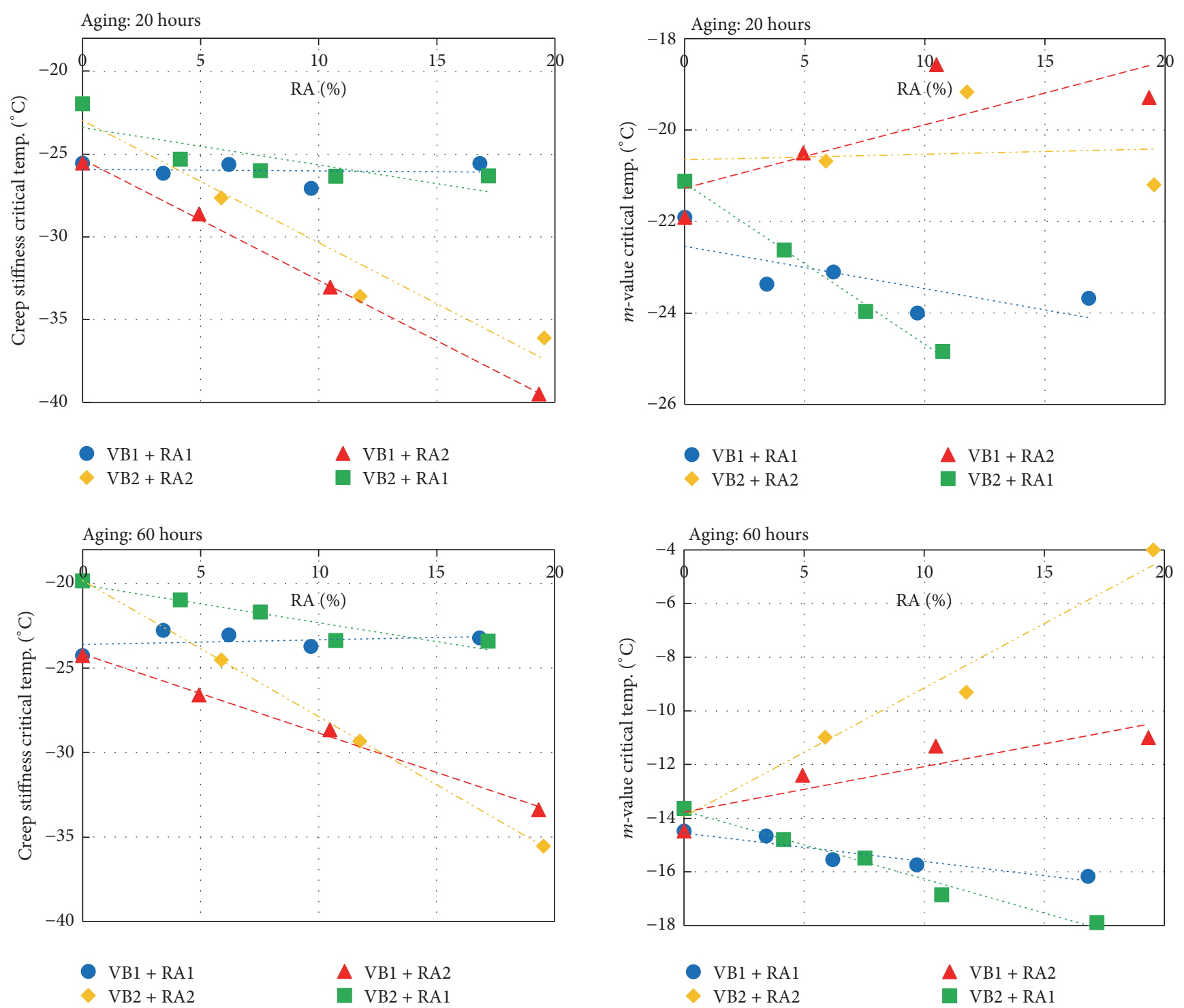

FIGURE 8: Variations of creep stiffness and $m$-value critical temperatures with the rejuvenator content.

due to the State Material Office, Bituminous Section, for its support and invaluable technical contribution.

\section{References}

[1] R. B. Mallick, K. A. O’Sullivan, M. Tao, and R. Frank, "Why not use rejuvenator for $100 \%$ RAP recycling?" in Proceedings of the Ransportation Research Board 89Th Annual Meeting, Washington DC, USA, 2010.

[2] J. R. Willis and M. Marasteanu, "Improved mix design, evaluation, and materials management practices for hot mix asphalt with high reclaimed asphalt pavement content," Tech. Rep. NCHRP Report 752, Transportation Research Board of the National Academies, Washington DC, Wash, USA, 2013.

[3] H. Haghshenas, H. Nabizadeh, Y. Kim, and K. Santosh, "Research on high-rap asphalt mixtures with rejuvenators and WMA additives," Tech. Rep., Department of Roads Research Reports, Lincoln, Neb, USA, 2016.
[4] A. Copeland, Reclaimed Asphalt Pavement in Asphalt Mixtures: State of Practice," McLean, VA, 2011.

[5] E. Rahmani, M. K. Darabi, D. N. Little, and E. A. Masad, "Constitutive modeling of coupled aging-viscoelastic response of asphalt concrete," Construction and Building Materials, vol. 131, pp. 1-15, 2017.

[6] M. Z. Alavi, E. Y. Hajj, and P. E. Sebaaly, "Significance of oxidative aging on the thermal cracking predictions in asphalt concrete pavements," in 8th RILEM International Conference on Mechanisms of Cracking and Debonding in Pavements, vol. 13, 2016.

[7] M. Hasaninia and F. Haddadi, "The characteristics of hot mixed asphalt modified by nanosilica," Petroleum Science and Technology, vol. 35, no. 4, pp. 351-359, 2017.

[8] C. Purdy, Y. Mehta, A. Nolan, and A. Ali, "Methodology to determine optimum rejuvenator dosage for 50 percent highrap mixture," in Transportation Research Board 96th Annual Meeting. 
[9] M. Zaumanis, R. B. Mallick, and R. Frank, "Determining optimum rejuvenator dose for asphalt recycling based on Superpave performance grade specifications," Construction and Building Materials, vol. 69, pp. 155-166, 2014.

[10] R. L. Terrel and D. R. Fritchen, "Laboratory performance of recycled asphalt concrete," in Recycling of Bituminous Pavements, pp. 104-122, 1978.

[11] D. Singh, M. Zaman, and S. Commuri, "A laboratory investigation into the effect of long-term oven aging on RAP mixes using dynamic modulus test," International Journal of Pavement Research and Technology, vol. 5, no. 3, pp. 142-152, 2012.

[12] A. W. Ali, Y. A. Mehta, A. Nolan, C. Purdy, and T. Bennert, "Investigation of the impacts of aging and RAP percentages on effectiveness of asphalt binder rejuvenators," Construction and Building Materials, vol. 110, pp. 211-217, 2016.

[13] M. Baqersad, A. Hamedi, M. Mohammadafzali, and H. Ali, "Asphalt mixture segregation detection: digital image processing approach," Advances in Materials Science and Engineering, vol. 2017, 6 pages, 2017.

[14] A. Ongel and M. Hugener, "Impact of rejuvenators on aging properties of bitumen," Construction and Building Materials, vol. 94, pp. 467-474, 2015.

[15] M. Mohammadafzali, H. Ali, J. A. Musselman, G. A. Sholar, S. Kim, and T. Nash, "Long-term aging of recycled asphalt binders: a laboratory evaluation based on performance grade tests," in Airfield and Highway Pavements 2015, Miami, Fla, USA.

[16] H. Ali and M. Mohammadafzali, "Long-term aging of recycled binders," Project number BDV29 Two 977-01, Florida Department of Transportation, 2015.

[17] U. Bahia Hussain and A. David, "The Pressure aging vessel (pav): a test to simulate rheological changes due to field aging," in ASTM Special Technical Publication 1241, pp. 67-88, 1995. 

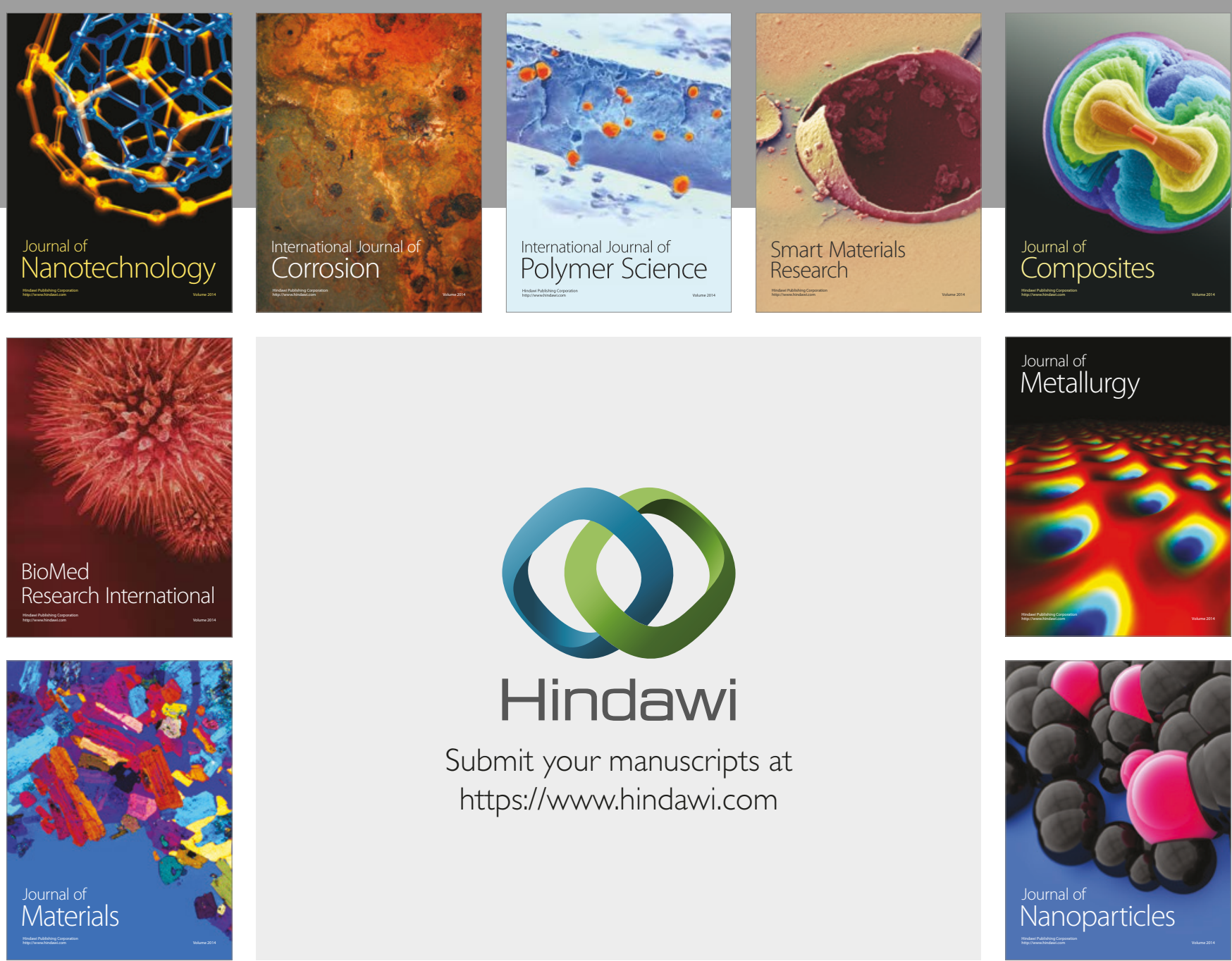

\section{Hindawi}

Submit your manuscripts at

https://www.hindawi.com
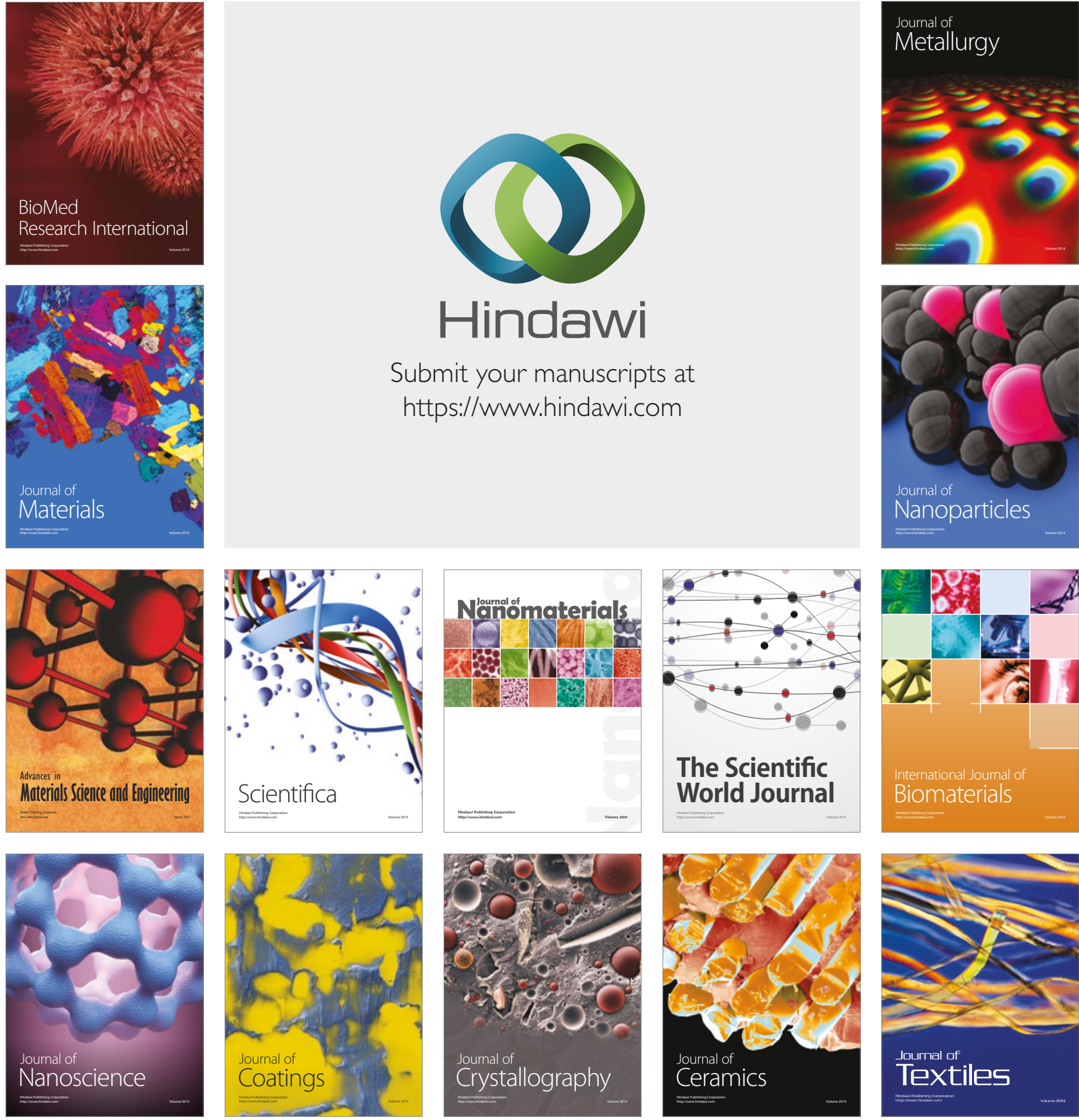

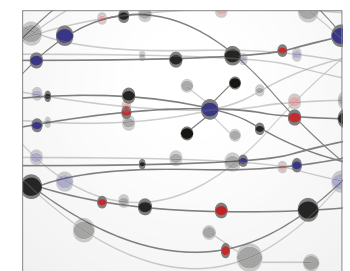

The Scientific World Journal
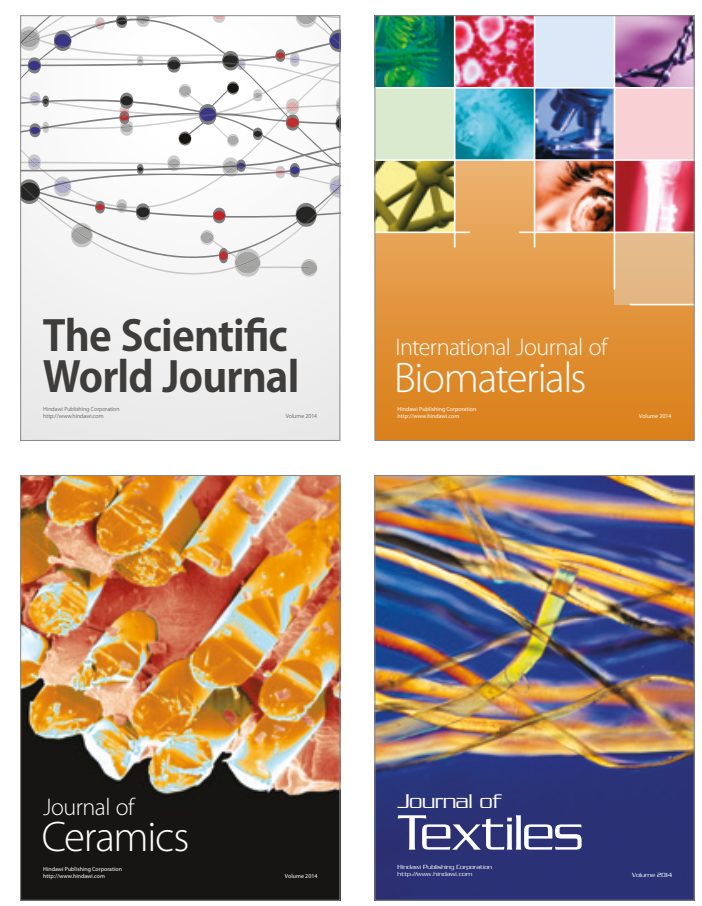